\title{
CONHECIMENTO CIENTÍFICO E FILOSOFIA: UMA DISCUSSÃO SOBRE $O$ MATERIALISMO DE IDENTIDADE A PARTIR DA FENOMENOLOGIA DE HUSSERL
}

\author{
José Aparecido Pereira ${ }^{1}$ \\ Pontifícia Universidade Católica do Paraná (PUC/PR) \\ (i) https://orcid.org/0000-0002-8298-8248
}

\begin{abstract}
RESUMO:
Na contemporaneidade, os debates na área da filosofia da mente no que tange ao cérebro e sua relação com a mente, predominantemente tem seguido os cânones da perspectiva materialista, representada pelas ciências empíricas, sobretudo pela neurociência. É tendo em vista esse tipo de abordagem, frente a um problema tão intrigante que, nesse artigo, pretendemos, por meio das categorias da fenomenologia de Husserl, analisar criticamente os argumentos de uma vertente do materialismo muito discutida no âmbito da filosofia da mente, a saber, o materialismo de identidade. Esse artigo encontra-se organizado e estruturado em torno de dois grandes momentos. Em primeiro lugar, o nosso objetivo consiste em demostrar quais são os aspectos mais relevantes que fundamentam as posições do materialismo de identidade no que diz respeito aos estudos sobre o problema mente e cérebro. Em seguida, a partir dos pressupostos teóricos da fenomenologia de Husserl, o nosso objetivo é demonstrar possíveis lacunas e inconsistências quanto a esse tipo de materialismo.
\end{abstract}

PALAVARAS - CHAVE: Materialismo; Mente; Cérebro; Consciência; Neurociência.

\section{SCIENTIFIC KNOWLEDGE AND PHILOSOPHY: A DISCUSSION OF MATERIALISM IDENTITY FROM THE PHENOMENOLOGY OF HUSSERL}

\footnotetext{
${ }^{1}$ Doutor em filosofia, professor da Pontifícia Universidade Católica do Paraná (PUC/PR), Paraná - Brasil, do Programa de Pós-Graduação em Gestão do Conhecimento nas Organizações da UniCesumar e pesquisador do Instituto Cesumar de Ciência, Tecnologia e Inovação (ICETI).
} 


\begin{abstract}
:
In contemporary times, the debates in the field of philosophy of mind when it comes to the brain and its relationship with the mind, predominantly has followed the canons of materialism, represented by the empirical sciences, particularly neuroscience. It is in view of this approach, compared to an intriguing problem in this article, we intend, through the categories of Husserl's phenomenology, reviewing the arguments of materialism shed much discussed within the philosophy of mind, namely, materialism identity. This article is organized and structured around two great moments. First, our objective is to demonstrate what are the most important aspects underlying the identity of materialism positions with regard to studies of the mind and brain problem. Then, from the theoretical assumptions of phenomenology of Husserl, our goal is to demonstrate possible gaps and inconsistencies regarding this kind of materialism.
\end{abstract}

KEY WORDS: Materialism; Mind; Brain; Consciousness; Neuroscience.

\title{
Introdução
}

No período contemporâneo, as discussões na área da filosofia da mente no que diz respeito ao problema mente e cérebro, predominantemente tem seguido as premissas da perspectiva materialista de matriz positivista. Isso se justifica por causa do surgimento de novas áreas do conhecimento que possibilitaram o desvelamento de intricados problemas relacionados ao cérebro humano. Áreas como as ciências cognitivas e a neurociência frequentemente têm fornecido respostas a problemas intrigantes quanto ao cérebro e sua relação com a mente e, paulatinamente, têm se tornado os referenciais para se discutir e investigar questões dessa natureza. Assim, as novas descobertas no âmbito dessas ciências possibilitaram o aparecimento de um grupo de adeptos e entusiastas que explicitamente demonstram extrema simpatia pelos resultados, supostos benefícios e performance dessas ciências. Em relação a isso vejamos a seguinte passagem: "não devemos minimizar a dimensão da revolução conceitual aqui indicada: ela seria enorme. Se cada um de nós tivesse uma compreensão neurocientífica precisa (que agora concebemos nebulosamente como) variedades e causas das doenças mentais, os fatores envolvidos no aprendizado, na base neural das emoções, na inteligência e na socialização, então a soma total da miséria humana poderia ser reduzida em muito. $\mathrm{O}$ simples aumento da compreensão mútua que esse novo arcabouço tornaria possível poderia contribuir em muito para uma sociedade mais pacífica e humana. Naturalmente, haveria perigos também: conhecimento maior significa poder maior, e o poder sempre pode ser mal-utilizado" (CHURCHLAND, 2004, p. 82).

Por causa disso, eles conduzem e encaminham as suas abordagens e as suas investigações sobre o problema mente e cérebro para a perspectiva 
da ciência moderna, sobretudo da neurociência, fazendo com que os seus argumentos e posicionamentos estejam bem alinhavados com essa ciência. Dessa forma, "o materialismo continua sendo associado à crença na ciência moderna e à sua capacidade de explicar tudo que possamos desejar sobre o mundo e sobre nós próprios. A ciência, para a qual La Mettrie apelava, era rudimentar e encontrava-se nos primórdios de seu desenvolvimento. Mas, meio aos séculos que se passaram o seu e o nosso tempo e, sobretudo na segunda metade do século XX" (MATTHEWS, 2005, p.35).

Tais pensadores fazem parte daquilo que passou a ser denominado de visão materialista. Essa corrente de pensamento, no contexto da filosofia da mente contemporânea, tem sido interpretada como uma vertente teórica muito relevante, passando a se configurar como uma das mais importantes no século XX e XXI. O fio condutor fundamental que norteia as suas reflexões em torno do problema mente e cérebro se encontra relacionado à intepretação segundo a qual os fenômenos mentais - tais como pensamento, vontade, dor, consciência e assim por diante - nada mais são do que reações e estados químicos e físicos do nosso cérebro. Portanto, é tendo em vista esse modo de conceber a relação entre mente e cérebro que, nesse artigo, pretendemos, por meio das categorias da fenomenologia de Husserl, analisar os argumentos e as posições de um tipo de materialismo muito recorrente no âmbito da filosofia da mente, qual seja, o materialismo da identidade.

A discussão que pretendemos desenvolver nesse artigo encontra-se estruturada em torno de dois grandes momentos. Inicialmente, a nossa intenção consiste em demostrar quais são os aspectos mais relevantes que fundamentam os argumentos dos teóricos do materialismo de identidade no que diz respeito aos estudos do problema mente e cérebro. Em seguida, a partir dos pressupostos teóricos da fenomenologia de Husserl, o nosso objetivo é destacar e demonstrar possíveis lacunas e inconsistências quanto a esse tipo de materialismo. Iniciemos, então, a nossa investigação realizando uma exposição sobre as ideias mais importantes dessa corrente.

\section{Os aspectos fundamentais do materialismo da identidade}

Comecemos a nossa abordagem apresentando uma citação na qual o assunto principal diz respeito ao materialismo e as suas pretensões de investigar o cérebro: "[...] nosso conhecimento sobre o cérebro e seus funcionamentos, apesar de imperfeito, atingiu um alto nível de sofisticação. Provavelmente e, em parte, devido a esse motivo, surgiu recentemente uma renovação de várias formas de materialismo no movimento analítico em filosofia" (MATTHEWS, 2005, p.35). A partir dessa passagem, podemos afirmar que o materialismo de identidade se constitui como uma dentre as diversas formas de materialismo na contemporaneidade. Uma das inquietações fundamentais dessa corrente de pensamento consiste em construir argumentos que refutassem duas perspectivas teóricas muito 
importantes no âmbito da filosofia da mente: o dualismo de substância, que se encontra enraizado desde a Idade Moderna, sobretudo a partir da filosofia de René Descartes e o dualismo de propriedades que emergiu no período contemporâneo a partir do pensamento de David Chalmers e Thomas Nagel. Em relação ao dualismo de substância, Churchland em seu texto Eliminative materialism and the propositional Attitudes (2004), afirma o seguinte: "A afirmação que caracteriza essa concepção é a de que cada mente é uma coisa não física distinta, um 'pacote' individual de substância não-física, uma coisa cuja identidade é independente de qualquer corpo físico ao qual ela possa estar temporariamente conectada". (CHURCHLAND, 2004, p. 27).

Quanto ao dualismo de propriedades: "a idéia de que estados mentais são uma propriedade especial ou um atributo específico de algumas porções da matéria da qual é composto o universo. [...] Essa propriedade especial emerge da substância material [...] o dualista de propriedades sustenta que tal propriedade especial não pode ser descrita em termos físicos. É o próprio cérebro que produz a subjetividade e os estados subjetivos, mas esses nunca poderiam ser integralmente mapeados em relação a estados cerebrais" (TEIXEIRA, 2001, p. 90-91).

Os representantes mais destacados do materialismo de identidade são U.T. Place que publicou um texto intitulado Será a consciência um processo do cérebro? (1956) e J.J Smart que publicou o artigo Sensações e processos cerebrais (1991). Ambos sustentam que a mente não pode ser concebida como um fenômeno distinto do cérebro. Isso significa dizer que para esses pensadores a mente e o cérebro são idênticos. Por isso, essa suposição os levará à afirmação de que todos os fenômenos mentais nada mais seriam que eventos cerebrais. Dessa maneira, a consciência, o pensamento e outras entidades psíquicas são entendidos como elementos físico-químicos. Nas linhas seguintes pretendemos explicitar os argumentos que eles elaboraram para sustentar essa interpretação.

O foco da discussão tanto de Place quanto de Smart encontra-se relacionado àquilo que fora denominado de condutivismo lógico, cujo representante de maior expressão foi Carnap. A sua maneira de conceber o condutivismo lógico pode ser expresso da seguinte maneira: "toda proposição de psicologia pode ser formulada em linguagem fisicalista. Para dizer isso num modo material de falar: todas as proposições de psicologia descrevem acontecimentos físicos, a saber, a conduta física dos humanos e dos outros animais. Essa é uma tese parcial da tese geral do fisicalismo que reza que a linguagem fisicalista é uma linguagem universal, isto é, uma linguagem a qual pode traduzir-se qualquer proposição" (CARNAP, 1978, p.171). Desse modo, o que se pretendia era fazer uma análise fisicalista das disposições para conduta a partir de um conjunto de conceitos, tais como, saber, crer, entender e recordar, bem como de termos relacionados à vontade, a saber, desejar, ter intenção de, e assim por diante. Mas na intepretação dos teóricos do materialismo de identidade era preciso estudar 
um conjunto de fenômenos mentais que pareciam não se coadunar com as pretensões do condutivismo lógico, ou seja, com as análises da disposição para a conduta. Desse modo, para eles, termos como sensação, experiência, consciência e imagem mental não deveriam ser estudados como disposições para a conduta, mas sim como ocorrências ou reações cerebrais. Isso implicará a diferenciação entre dois campos: atitudes intencionais (crenças, desejos e intenções) e estados fenomenológicos (sensações e experiências). Smart e Place são unânimes em afirmar que uma interpretação fisicalista das atitudes intencionais em termos condutivistas seria até plausível e aceitável. Entretanto, eles reivindicam que o resíduo dos estados fenomenológicos fosse incorporado a uma interpretação materialista e fisicalista no que tange à natureza dos fenômenos mentais. Desse modo, as experiências das qualidades sensíveis das coisas, de frio e de calor, de prazer e de dor, bem como as imagens mentais estariam fazendo referência a uma visão materialista do mundo. Em outras palavras, estariam relacionados às atividades cerebrais. Assim, a posição dos defensores da teoria da identidade parece se encaminhar para uma espécie de reducionismo onde os fenômenos mentais deveriam ser reduzidos a estados cerebrais. Portanto, as investigações sobre a mente humana passariam a ser consideradas como uma ramificação da neurociência ou da neurofisiologia.

Outro aspecto importante refletido pelo materialismo de identidade de Smart e de Place encontra-se relacionado à questão dos objetos privados, muito discutido na filosofia cartesiana e que, posteriormente, Carnap chamou de protocolos introspectivos. No pensamento de Descartes, as proposições psicológicas relacionadas a sensações, crenças, vontades, desejos etc. foram definidas como restritas a primeira pessoa e compreendidas como sendo de natureza não física, ou seja, de ordem metafísica e imaterial. Ora, se essa interpretação cartesiana estiver correta, então a análise nos moldes fisicalista deve ser considerada inconsistente e lacunar, porque não conseguiria explicar a existência de entidades que transcendem a dimensão física e material. A sugestão de Carnap para esse problema foi que proposições como tenho dor, e outras da mesma natureza, deveriam ser investigadas sob o prisma do condutivismo lógico, pois estariam fazendo alusão a proposições psicológicas que estão vinculadas à realidade da conduta do indivíduo. Isso significa dizer que elas não podem ser vistas como sendo não físicas e imateriais, conforme sugeriu Descartes. Em relação a isso, tanto o posicionamento de Smart quanto o de Place convergirão para a intepretação de Carnap. Para eles, não há argumento plausível para acreditarmos que quando alguém está relatando enunciados que expressam sensações, desejo, vontade, dor e assim por diante, estaria fazendo referência a entidades não físicas e imateriais: "Para Smart, parece existir apenas uma possibilidade: a de que experiências conscientes, como ter dores e outras sensações ou possuir imagens residuais, são apenas processos cerebrais - que são literal e estritamente idênticas àquilo que 
acontece no cérebro quando alguém vivência uma dessas experiências" (MATTHEWS, 2005, p. 40).

Place argumenta que as experiências subjetivas não deveriam ser consideradas como relações com os objetos imateriais intercalados entre a pessoa e os objetos físicos públicos. Para ele, a explicação para o fato de alguém poder descrever as suas experiências introspectivas não nos deveria induzir à crença na existência de objetos não físicos. Assim, segundo o autor, defender a interpretação segundo a qual os enunciados introspectivos devem ser entendidos como entidades não físicas significa cair no que ele denominou de falácia fenomenológica: "esse erro lógico a que me refiro como a 'falácia fenomenológica' é o erro de supor que quando o sujeito descreve sua experiência, quando descreve como as coisas lhes parecem [...] como as sente, está descrevendo as propriedades literais de objetos e eventos num tipo peculiar de tela interna de cinema ou televisão, conhecida normalmente na bibliografia psicológica contemporânea como o "campo fenomênico" (PLACE, 1956, p. 35). Assim, na sua visão, nas experiências conscientes subjetivas o que acontece é, de fato, a descrição de processos internos. Entretanto, eles não são de caráter não físico. Para Place, esses processos encontram-se localizados no cérebro. Por isso que ele acredita na possibilidade de se relacionar os fenômenos mentais a um padrão específico de ocorrências cerebrais e que, hipoteticamente, poderiam existir fundamentos científicos para a demonstração dessa tese. Mas isso seria possível, se somente se, a evidência empírica pudesse relacionar as observações introspectivas de uma pessoa a uma gama de processos cerebrais.

Todavia, Place adverte que essa suposição não pode ser considerada como uma teoria filosófica, mas como uma conjectura científica. A sua expectativa é que as pesquisas científicas no âmbito da neurociência poderão evidenciar que os fenômenos mentais seriam sim idênticos aos processos cerebrais. Dessa maneira, eles não mais deveriam ser interpretados como ocorrências de alguma substância mental não física ou imaterial. Para Place, a filosofia teria um papel extremamente fundamental nesse processo: estaria sob a sua responsabilidade a demonstração da não existência de argumentos que pretendesse refutar a hipótese da identidade como racionalmente plausível. Em relação a isso, "um argumento filosófico comum contra a identificação da consciência com processos cerebrais é o de que a expressão 'consciência', claramente não possui o mesmo significado da expressão 'processo cerebral' [...] Place aceita essa hipótese completamente, mas nega que esteja relacionada à tese que ele tenta estabelecer" (MATTHEWS, 2005, p. 37-38).

A abordagem que fizemos até aqui sobre o materialismo de identidade a partir do pensamento de Place e Smart nos sugere as seguintes questões: qual a natureza da das teses do materialismo de identidade? Como deve ser interpretada a suposição de que os fenômenos mentais nada mais 
são que ocorrências localizadas no cérebro? Quando se pensa em identidade o propósito não é fundamentá-la a partir da necessidade lógica como a que ocorre no âmbito da matemática e da geometria, como um triângulo, por exemplo. Fala-se aqui de identidade no sentido de contingência. Com isso, os defensores da teoria da identidade pretendem sugerir a identidade entre os fenômenos mentais de um tipo determinado com fenômenos do sistema nervoso cerebral também de um tipo determinado. Assim, segundo seus proponentes, essa teoria deve ser vista e entendida como uma hipótese científica e que os avanços e progressos das ciências físicas, sobretudo no âmbito da neurofisiologia, haverão de corroborá-la. Em relação a isso, Place se posiciona do seguinte modo: "a proposição a 'consciência é um processo no cérebro', não é em minha opinião nem autocontraditória nem autoevidente; constitui uma hipótese científica razoável, da mesma forma que o enunciado 'um relâmpago é um movimento de cargas elétricas' é uma hipótese científica razoável” (PLACE, 1956, p. 30). Enfim, os defensores dessa teoria sustentam que, de maneira contingente, no mundo real um predicado mental denota a mesma propriedade que um determinado predicado físico, ou seja, uma determinada propriedade neurofisiológica. Portanto, assim como não podemos provar ou refutar a proposição "a temperatura de um fluído é a energia cinética molecular média das moléculas que o compõe" por meio um estudo semântico dos termos que o estruturam, também não seria possível provarmos ou refutarmos a proposição “os estados da consciência são estados do cérebro". Por conseguinte, esse tipo de problema somente poderia ser elucidado a partir de análises de caráter empírico.

A abordagem anterior nos mostra claramente que os estudos e as discussões sobre a relação entre a mente e o cérebro no âmbito do materialismo de identidade têm sido orientados pelos pressupostos teóricos do pensamento positivista, para o qual tanto a ciência quanto a técnica constituem as referências fundamentais de interpretação e compreensão do mundo. Desse modo, o enfoque epistemológico tecnicista e cientificista de inspiração marcadamente positivista, representado, sobretudo pela neurociência e pelas outras ciências da natureza, privilegia uma concepção objetivista, fisicalista e materialista da mente e do cérebro, orientada por princípios descritivos, quantitativos e analíticos. Isso de certa forma tem a sua relevância e sua importância, mas entendemos que essa maneira de estudar um problema tão antigo e tão intrigante se revela também muito reducionista e limitada, haja vista a sua incapaciade de dar conta de muitos outros aspectos igualmente importantes nos estudos sobre o assunto em questão. Por isso, acreditamos que a perspectiva fenomenológica pode contribuir significativamente com os estudos da relação entre mente e cérebro, sendo capaz de demonstrar lacunas e inconsistências quanto ao materialismod e identidade. 


\title{
Uma análise sobre o materialismo de identidade a partir da fenomenologia de Husserl
}

Podemos afirmar que Edmund Husserl (1859-1938) é considerado consensualmente como o fundador e, ao mesmo tempo, o sistematizador da fenomenologia enquanto corrente de pensamento do período contemporâneo. As suas reflexões filosóficas se desenvolveram como um protesto em relação ao psicologismo e ao naturalismo muito difundidos nos ambientes acadêmicos na Alemanha. $\mathrm{Na}$ sua interpretação, a atmosfera cultural e intelectual do ocidente encontrava-se numa profunda crise e decadência de proporções consideráveis pelo fato das ciências se orientarem por perspectivas marcadamente naturalistas e objetivistas que viam a realidade como algo que pode ser medido, quantificado e calculado, inclusive elementos constituivos da dimensão psiquica do ser humano. A posição de Husserl frente a essa situação foi extremamente crítica, porque para ele esses procedimentos eram muito ingênuos, visto que tudo era reduzido aos protocolos materialistas e fisicalistas da ciência. A citação a seguir expressa claramente a sua visão:

\begin{abstract}
É verdade que após terem se desenvolvido de forma brilhante durante três séculos, as ciências se vêm hoje bloqueadas em seu progresso pela obscuridade que reina em seus próprio fundamentos (...) $\mathrm{O}$ estado de divisão no qual se encontra atualmente a filosofia, a atividade desordenada que ela empreende nos levam a pensar. Do ponto de vista da unidade científica, a filosofia ocidental encontra-se, desde meados do século passado, num visível estrado de decadência em relação à épocas precedentes. Por toda parte desapareceu a unidade: tanto na determinação do objetivo, quanto na colocação dos problemas e no método. (HUSSERL, 2001, p.22)
\end{abstract}

Como legado do seu mestre, Franz Brentano, Husserl considerou a retomada da concepção aristotélica de intencionalidade, interpretada como a direção da consciência ao objeto, ao real, que é definidora da própria consciência, constituindo-se como uma categoria fundamental da sua filosofia. Mas a sua filosofia pode ser vista, também, como uma versão contemporânea do idealismo transcendental esboçado e desenvolvido por Kant na Idade Moderna. Enfim, as influências do seu pensamento no período contemporâneo, principalmente sobre filósofos como Heidegger, Sartre, Scheller e outros foram significativas e marcantes.

Como salientamos anteriormente, a perspectiva predominante nos estudos contemporâneos sobre a mente e sua relação com o cérebro encontra-se relacionada à visão materialista de matriz positivista. Quando falamos da mente e do cérebro como um problema não podemos nos esquecer que subjacente às intricadas questões relacionadas a ele existe um ser humano em sua dimensão pessoal, ou seja, enquanto pessoa ou 
subjetividade. Isso nos permite inferir que o problema mente e cérebro evidencia também uma dimensão antropológica, o que, a nosso ver, impõe sérios problemas para as tentativas de se compreendê-lo sob a perspectiva da neurociência como acreditam os adeptos do materialismo de identidade. É que existem aspectos inerentes à existência humana que não são redutíveis a uma intepretação alinhada com as categorias da neurociência. Em outras palavras, a perspectiva fisicalista, objetivista e materialista, tão característica dessa área, não pode dar conta de fenômenos relacionados à mente e ao cérebro e que significativamente dinamizam a existência do ser humano: fenômenos ligados às vivências psíquicas e existenciais, reduto das motivações, sonhos, frustrações, fracassos, miséria, sofrimento, glórias, inseguranças e conquistas do humano. Em relação às vivências entendidas como fenômeno, Edmund Husserl afirma o seguinte:

[...] chamaremos de fenômeno tudo aquilo que é vivência, na unidade de vivência de um eu: a fenomenologia é, por conseguinte, a doutrina das vivências gerais, abrangendo também a doutrina de todos os dados, não só os genuínos, mas também os intencionais, que podem ser evidenciados nas vivências. (HUSSERL, 1988, p.176)

Como podemos notar, nessa citação, Husserl faz alusão a dois aspectos fundamentais: as vivências gerais e todos os dados. A questão a ser levantada a partir disso é a seguinte: as categorias e os procedimentos da neurociência e das ciências empíricas conseguiriam tornar explícito esses aspectos? A nosso ver, a resposta a essa questão deve ser negativa. Assim, existem vivências humanas que não podem ser explicadas e nem alinhadas com a visão reducionista e fisicalista subjacentes ao materialismo de identidade. Dessa maneira, os mecanismos tecnicistas e cientificistas do enfoque neurocientífico parecem ser insuficientes para promover um desvelamento das vivências gerais e de todos os dados.

Mas a citação acima também faz referência a outro aspecto relevante e que pode ser tomado como pressuposto para se fazer uma análise crítica sobre as teses do materialismo de identidade. Observemos que nela Husserl fala explicitamente dos dados intencionais ou da intencionalidade. A questão da intencionalidade é um tema constitutivo da fenomenologia de Husserl e se encontra em estreita relação com outra temática, a saber, a redução fenomenológica ou a epoché:

Fazer epoché não significa propriamente duvidar. Fazer epoché significa muito mais suspender o juízo, antes de mais nada, sobretudo o que nos dizem as doutrinas filosóficas, com seus inconcludentes debates metafísicos sobre o que dizem as ciências, sobre aquilo que cada um de nós afirma e pressupõe na vida cotidiana, isto é, sobre crenças que tecem aquilo que Husserl chama de atitude natural. (REALE \& ANTISERI, 1991, p. 563)

conhecimento científico e filosofia: uma discussão sobre o materialismo de identidade a partir da fenomenologia de Husserl - José Aparecido Pereira 
Para Husserl, no ato de suspensão do juízo o elemento que resiste à redução à epoché, ou seja, que não se pode suspender é a consciência. Nesse sentido, "Pode-se dizer assim que a epoché é o método universal e radical pelo qual me percebo como eu puro, com a vida de consciência pura que me é própria, vida na qual e pela qual todo mundo objetivo existe para mim exatamente da forma que existe para mim. Tudo o que é 'mundo', todo o ser espacial e temporal existe para mim, quer dizer, vale para mim; o próprio fato de eu ter dela a experiência, de percebê-lo, rememorá-lo, pensar nele de qualquer maneira, elaborar em relaçào a ele julgamentos de existência ou de valor, desejá-lo e assim por diante" (HUSSERL, 2001, p.38.). Assim, a consciência (enquanto substrato da subjetividade) é o resíduo que resiste a redução fenomenológica. Entretanto, ela é sempre intencional. Ou seja, nunca está vazia. Está sempre mirando e visando algo. Essa capacidade da consciência em não estar vazia e sempre estar visando alguma coisa, o filósofo a chamou de intencionalidade: "Esses estados de consciência são também chamados estados intencionais. A palavra intencionalidade não significa nada mais que essa particularidade fundamental e geral que a consciência tem de ser consciência de alguma coisa, de conter, em sua qualidade de cogito, seu cogitatum em si mesma" (HUSSERL, 2001, p. 51). O desdobramento dessa interpretação o levou também a sustentar que a consciência humana é sempre doadora de sentido e significado. Convém dizer que, a partir do pensamento fenomenológico o termo sentido e significado passaram a ser designados como a essência da realidade. Portanto, consciência, intencionalidade e sentido devem ser vistos como conceitos indissociáveis e inseparáveis, ou seja, formam um bloco unitário. E na perspectiva de Husserl esses conceitos possuem também uma relação intrínseca com o que ele chamou de fenômenos.

Acreditamos que a questão do sentido e do significado como atividade da consciência constitui um aspecto importante para se questionar as teses e os argumentos do materialismo de identidade e, por consequência, as pretensões da neurociência. Falamos ainda a pouco das vivências intencionais como um dado inerente às pessoas e que, por isso, encontramse também relacionados à mente e ao cérebro. O sentido ou o significado é um tipo de vivência relacionada à dimensão existencial dos seres humanos e também, de certo modo, está relacionado à dinâmica do cérebro e da mente. Sendo assim, a questão é esta: como a tese fundamental do materialismo de identidade segundo a qual os fenômenos mentais nada mais são que ocorrências cerebrais poderiam explicar o problema do sentido e do significado a partir de uma linguagem fisicalista, própria da neurociência? Diríamos que a perspectiva positivista e neurocientífica orientada pelos procedimentos experimentais, fisicalistas e quantitativos não é suficiente e não pode dar conta dessa questão, pois o problema do sentido e do significado transcende o domínio do empírico. Ou seja, eles não são 
redutíveis a nenhuma base experimental ou fisicalista. Para essa questão, acreditamos que a perspectiva neurocientífica não poderia oferecer uma resposta universalmente padronizada, visto que a questão do sentido e do significado se encontra enraizado no domínio da subjetividade. (NAGEL, 2005, p. 247 - 248) Por isso, a linguagem fisicalista da ciência e da neurociência não consegue descrever ou perscrutar o horizonte do sentido e do significado que se encontra intrinsecamente vinculado às experiências conscientes (vivências significativas) dos indivíduos: "Na miséria da nossa vida, [...] essa ciência não tem nada a nos dizer. Em princípio, ela exclui aqueles problemas que são os mais candentes para o homem, o qual, em nossos tempos atormentados, sente-se à mercê do destino: os problemas do sentido e do não sentido da existência humana em seu conjunto" (HUSSERL, 1954, p. 10).

Enfim, essa citação da obra de Husserl nos sugere explicitamente que a nossa relação com o mundo ou a realidade não é somente uma relação epistemológica, ou seja, de conhecimento. A nossa relação com o mundo é também de outra ordem: sentido e significado. Disso decorre que, quanto mais sentido e significado algo tiver em nossa existência, mais importante ele é para nós. Isso implica em estabelecer uma nova relação entre o homem e o mundo, haja vista que eles são dois pólos inseparáveis: "Portanto, sou eu o pólo subjetivo da vida transcendental na qual, em primeiro lugar, o mundo tem sentido para mim puramente como mundo: em minha plena concretude, eu abranjo tudo isso" (HUSSERL, 2006, p. 123). Sendo assim, as análises sobre o cérebro e sua relação com a mente, por serem elementos constitutivos da subjetividade, não deveriam ser orientadas apenas por uma significação unilateral, conforme propõem os seguidores do materialismo de identidade por meio da neurociência.

\section{Considerações finais}

No decorrer desse artigo, procuramos evidenciar que as discussões sobre o problema mente e cérebro na filosofia da mente contemporânea têm sido orientadas pela perspectiva materialista, tendo a neurociência e as ciências empíricas como as suas principais representantes. Em relação ao materialismo de identidade, vimos que a sua tese fundamental se baseia na crença de que os fenômenos mentais, e outros da mesma natureza, nada mais são do que ocorrências localizadas no cérebro. Assim, a proposta advinda dessa corrente de pensamento demonstra explicitamente a tentativa de solucionar um problema tão complexo sob uma orientação reducionista, circunscrita às premissas da ciência e da técnica. Essa tentativa parece conter, implicitamente, um posicionamento extremamente cientificista e, ao mesmo tempo, e antifilosófico, uma vez que procura conceder à neurociência a primazia no que tange aos problemas relativos à natureza do cérebro e sua relação com a mente. Entretanto, pelo seu caráter e natureza, a 
mente constitui genuinamente uma questão marcadamente metafísica, esfera a qual somente a filosofia pode investigar. Nesse sentido, podemos afirmar que a mente constitui uma problemática mais de caráter filosófico e não científico. Por conta disso, entendemos que o debate contemporâneo sobre os problemas relacionados à mente e ao cérebro deveria ser orientado por uma perspectiva interdisciplinar no qual as diversas áreas do conhecimento humano deveriam ser instigadas a dar as suas contribuições. 


\section{Referências bibliográficas}

CARNAP, R. Psicologia en lenguaje fisicalista, en A. J. Ayer (ed.), El positivismo lógico. México: Fondo de Cultura Económica, 1978, pp. 171204

CHURCHLAND, Paul. Eliminative materialism and the propositional Attitudes. In John Heil (ed.), Phylosophy of Mind: A guide and anthology. Oxford: Oxford Unversity Press, 2004, pp. 382-400

Matéria e consciência - uma introdução contemporânea à

filosofia da mente. Tradução: Maria Clara Cescato. São Paulo: Editora UNESP, 2004.

HUSSERL, Edmund. A crise das ciências europeias e a Fenomenologia Transcendental. Paris: Gallimard, 1954.

Ideias para uma fenomenologia pura e uma filosofia fenomenológica: introdução geral à fenomenologia pura. Tradução de Márcio Suzuki. Aparecida, SP: ideias \& letras, 2006. Meditações Cartesianas. S. Paulo: Ed. Madras, 2001.

MASLIN, K. T. Introdução à filosofia da mente. Porto Alegre: Artmed, 2009

MATTHEWS, Eric. Mente: conceitos-chaves em filosofia. Porto Alegre: Artmed, 2005

NAGEL, Thomas. Como é ser como um Morcego? Tradução: Paulo Abrantes. In: Cadernos de História da Filosofia da. Ciência. Campinas, Série 3, v. 15, n. 1, p. 245-262, jan.-jun. 2005.

PLACE, U. T. Is consciousness a brain-process? British Journal of Philosophy, 1956, pp. 44-50

REALE, Giovanni \& ANTISERI, Dario. História da filosofia Vol. III. São Paulo: Paulus, 1991.

SMART, J. J. Sensations and brain-process, reiprinted in D.M. Rosenthal (ed.), The Nature of Mind, Oxford, Oxford University Press, 1991, pp. 169176

TEIXIERA, João de Fernandes. A mente pós-evolutiva. Petrópolis, RJ: Vozes, 2010. Mente, cérebro e cognição. Petrópolis, RJ: Vozes, 2000. 